\title{
Retraction Note to: TNF receptor-associated factor 6 regulates proliferation, apoptosis, and invasion of glioma cells
}

\author{
Zhang Peng $^{1} \cdot$ Yue Shuangzhu ${ }^{1} \cdot$ Jiang Yongjie $^{2} \cdot$ Zhang Xinjun $^{3} \cdot$ \\ Liu Ying ${ }^{2}$
}

Published online: 18 March 2016

(C) Springer Science+Business Media New York 2016

\section{Retraction Note to: Mol Cell Biochem (2013) \\ 377:87-96 \\ DOI 10.1007/s11010-013-1573-2}

The Editor-in-Chief retracts this article as per the Committee on Publication Ethics (COPE) guidelines on plagiarism. After a thorough investigation, it was found that there is a striking level of similarity in the layout and content of this paper with another publication (Tumor Biology (2013) 34:231-239; doi:10.1007/s13277-0120543-8). It is also pointed out that the authors have failed to respond to these similarity issues, first brought to their attention in 2015 .

The online version of the original article can be found under doi:10.1007/s11010-013-1573-2.

Zhang Peng

zhangpeng_hn@163.com

1 Department of Neurosurgery, The First Affiliated Hospital of Xinxiang Medical University, No. 88, Jian-kang Road, Xinxiang 453100, Henan, China

2 Department of Gynaecology and Obstetrics, The First Affiliated Hospital of Xinxiang Medical University, Xinxiang 453100, China

3 Department of Urology, The First Affiliated Hospital of Xinxiang Medical University, Xinxiang 453100, China 